УДК 547.295; 547.92

\title{
ХИМИЧЕСКИЙ СОСТАВ КОМПОНЕНТОВ ВОДНО-ПАРОВОГО ДИСТИЛЛЯТА И ЭКСТРАКТОВ, ПОЛУЧЕННЫХ С ПРИМЕНЕНИЕМ ОРГАНИЧЕСКИХ РАСТВОРИТЕЛЕЙ ИЗ СЫРЬЯ ГРИБА ЧАГИ
}

\author{
(C) Ю.Г. Слижов, В.В. Хасанов, А.А. Чумаков*
}

\author{
Национальный исследовательский Томский государственный университет, \\ пр. Ленина, 36, Томск, 634050 (Россия), e-mail: anton.doktor.tomsk@mail.ru
}

\begin{abstract}
Исследован химический состав компонентов водно-парового дистиллята и экстрактов, полученных с применением органических растворителей из природного лекарственного сырья березового гриба чаги Inonotus obliquus (Pers.) Pilat. Соединения, извлекаемые из чаги перегонкой водяным паром, более чем на $90 \%$ состоят из насыщенных и ненасыщенных высших жирных кислот с 16-18 атомами углерода (ВЖК $\left.\mathrm{C}_{16}-\mathrm{C}_{18}\right)$. Гексан, хлороформ и этилацетат экстрагируют из чаги ВЖК $\mathrm{C}_{16}$ и $\mathrm{C}_{18}$ и тетрациклические тритерпеноидные соединения. Количественный выход экстракта в расчете на массу сырья при одинаковых условиях и длительности экстракции обратно пропорционален полярности органического растворителя. Среди тритерпеноидов преобладают специфические компоненты чаги - инотодиол (доминирующий компонент), траметеноловая кислота и ее альдегид, составляющие вместе 50-60\% компонентов экстрактов, полученных с применением гексана, хлороформа или этилацетата. Поскольку инотодиол является биологически активным соединением, проявляющим in vitro выраженную противоопухолевую активность, то извлечение специфических ланостановых тритерпеноидов из чаги с помощью органических растворителей актуально для их дальнейших экспериментальных и клинических фармакологических исследований.
\end{abstract}

Ключевые слова: чага, Inonotus obliquиs (Pers.) Pilat, карбоновые кислоты, тритерпеноиды.

\section{Введение}

Актуальным направлением современных научных исследований является поиск биологически активных соединений в составе лекарственных растений и грибов [1]. Вид Inonotus obliquus (Pers.) Pilat известен как березовый гриб чага. Его природные ресурсы ограничены [2], что требует их рационального использования - максимального извлечения фармакологически активных компонентов. Для эффективной переработки нужны данные об извлекаемости компонентов сырья разными методами. К настоящему времени изучен в большей степени состав водных и спиртовых экстрактов чаги [3-10].

Цель работы - исследование состава соединений, извлекаемых из чаги перегонкой водяным паром и органическими экстрагентами различной полярности - гексаном, хлороформом, этилацетатом.

\section{Экспериментальная часть}

Для исследования использовали сырье Inonotus obliquus (Pers.) Pilat, собранное в сентябре 2013 г. в лесах Первомайского района Томской области вдали от автомобильных трасс, промышленных предприятий и населенных пунктов. Высушенное и измельченное сырье подвергли водно-паровой дистилляции и экстракции с применением разных органических растворителей.

Слижсв Юрий Геннадьевич - кандидат химических наук, декан химического факультета, заведующий кафедрой органической химии, e-mail: dekanat@xf.tsu.ru Хасанов Виктор Вазикович - кандидат химических наук, доцент кафедры органической химии,

e-mail: xasanov@chem.tsu.ru

Чумаков Антон Александрович - врач-биохимик, магистрант кафедры органической химии, e-mail: anton.doktor.tomsk@mail.ru
При водно-паровой дистилляции конденсат пропускали через концентратор, заполненный полимерным сорбентом Strata-X (200 мг, гранулирование 30 мкм, Phenomenex, США). Элюцию сорбированных соединений проводили раствором 0,160,20 мг/мл $\mathrm{Na}_{2} \mathrm{CO}_{3}$ в 85\% этаноле. Элюат высушивали в токе азота до полного удаления воды и спирта.

\footnotetext{
* Автор, с которым следует вести переписку.
} 
Экстракцию сырья проводили гексаном, хлороформом и этилацетатом путем его кипячения в растворителе с обратным холодильником в течение двух часов при соотношении «сырье : экстрагент»= «1 : 20» (г : мл). Охлажденные экстракты отделяли от шрота и высушивали в токе азота до полного удаления органического растворителя. В таблице 1 приведены результаты измерения массы сухих остатков органических экстрактов в расчете на массу навески сырья. К сухим остаткам элюата и экстрактов добавляли 50 мкл силилирующего реагента (BSTFA, Sigma-Aldrich) и 150 мкл пиридина, нагревали 1,5-2 мин при $80{ }^{\circ} \mathrm{C}$, после охлаждения переносили в микровиалы для газовой хроматографии-масс-спектрометрии (ГХMC). Разделение осуществляли на приборе Agilent 7890/5975C (Agilent Technologies, США) с колонкой DB-5ms (J\&W, CШA) 30 м × 0,25 мм, толщина фазы 0,25 мкм. Режим программирования температуры: $130{ }^{\circ} \mathrm{C} 2$ мин, $+20{ }^{\circ} \mathrm{C} /$ мин до $290^{\circ} \mathrm{C}, 290^{\circ} \mathrm{C} 25$ мин. Температура испарителя $-280{ }^{\circ} \mathrm{C}$, переходной линии $290{ }^{\circ} \mathrm{C}$, ионного источника - $230{ }^{\circ} \mathrm{C}$, квадруполя - $150{ }^{\circ} \mathrm{C}$. Скорость потока газа-носителя (гелия) $1 \mathrm{~cm}^{3} / \mathrm{Mин}$ (постоянный расход). Ввод пробы - без деления потока, 0,5 мкл. Ионизация - электронным ударом 70 эВ. Идентификация компонентов - по масс-спектрам с использованием библиотек NIST'08, Wiley и литературных данных $[8,11]$. Результаты (в процентах от суммы зарегистрированных компонентов) представлены в таблице 2.

Таблица 1. Масса сухих остатков органических экстрактов чаги, мг/г сырья

\begin{tabular}{c|c|c}
\hline Гексановый экстракт & Хлороформный экстракт & Этилацетатный экстракт \\
\hline 2,2 & 1,2 & 0,7 \\
\hline
\end{tabular}

Таблица 2. Компоненты водно-парового дистиллята и органических экстрактов чаги, \%

\begin{tabular}{|c|c|c|c|c|}
\hline \multirow{2}{*}{ Соединения } & \multirow{2}{*}{ Дистиллят } & \multicolumn{3}{|c|}{ Экстракты } \\
\hline & & Гексан & Хлороформ & Этилацетат \\
\hline Валериановая (пентановая) кислота & 0,6 & - & - & - \\
\hline Капроновая (гексановая) кислота & 1,3 & - & - & - \\
\hline Энантовая (гептановая) кислота & 0,5 & - & - & - \\
\hline Каприловая (октановая) кислота & 0,5 & - & - & - \\
\hline 2-Октеновая кислота & 0,3 & - & - & - \\
\hline Пеларгоновая (нонановая) кислота & 0,7 & - & - & - \\
\hline Каприновая (декановая) кислота & 0,4 & - & - & - \\
\hline Лауриновая (додекановая) кислота & 0,5 & - & - & - \\
\hline Миристиновая (тетрадекановая) кислота & 1,1 & - & - & - \\
\hline Пентадекановая кислота & 0,4 & - & - & - \\
\hline Пальмитолеиновая (Z-9-гексадеценовая) кислота & 6,7 & 2,0 & 1,3 & 2,8 \\
\hline Пальмитиновая (гексадекановая) кислота & 19,8 & 3,9 & 3,4 & 6,9 \\
\hline Маргариновая (гептадекановая) кислота & 0,7 & - & - & - \\
\hline Линолевая (Z,Z-9,12-октадекадиеновая) кислота & 55,2 & 16,1 & 14,3 & 23,5 \\
\hline Олеиновая (Z-9-октадеценовая) кислота & 6,8 & 3,1 & 2,2 & 5,1 \\
\hline Стеариновая (октадекановая) кислота & 2,9 & 0,7 & 0,5 & 1,3 \\
\hline Холестерин & 0,7 & - & - & - \\
\hline Эргостерин & 1,0 & 2,9 & 2,7 & 2,4 \\
\hline Эргоста-5,7,9(11),22-тетраен-3ß-ол & - & 0,7 & 0,6 & 0,3 \\
\hline Эргоста-7,22-диен-3ß-ол & - & 0,8 & 0,5 & 0,2 \\
\hline Эргоста-7-ен-3ß-ол & - & 0,5 & 0,4 & 0,1 \\
\hline$\beta$-Ситостерин & - & 0,3 & 0,2 & 0,2 \\
\hline Ланостерин (ланоста-8,24-диен-3ß-ол) & - & 11,3 & 10,3 & 7,4 \\
\hline Инотодиол (ланоста-8,24-диен-3ß,22R-диол) & - & 50,7 & 48,2 & 44,3 \\
\hline $\begin{array}{l}\text { Траметеноловая ( } 3 \beta \text {-гидроксиланоста-8,24-диен-21- } \\
\text { овая кислота) кислота }\end{array}$ & - & 2,6 & 11,5 & 2,2 \\
\hline 3ß-Гидроксиланоста-8,24-диен-21-аль & - & 4,5 & 4,0 & 3,4 \\
\hline
\end{tabular}

\section{Обсуждение результатов}

Перегонка водяным паром извлекает из чаги насыщенные и ненасыщенные карбоновые кислоты $\mathrm{C}_{5}-$ $\mathrm{C}_{18}$ и незначительно стерины (эргостерин, холестерин). Преобладают высшие жирные кислоты (ВЖК) $\mathrm{C}_{16}-$ $\mathrm{C}_{18}$, составляющие более $90 \%$ компонентов дистиллята.

Органические растворители извлекают из чаги ВЖК $\mathrm{C}_{16}$ и $\mathrm{C}_{18}$ и тетрациклические тритерпеноидные соединения - производные ланостана, эргостановые стерины, ситостерин. Суммарное количественное со- 
держание компонентов обратно пропорционально полярности экстрагента (гексан < хлороформ < этилацетат, табл. 1). Кроме того, физико-химические свойства растворителя влияют на соотношение компонентов (табл. 2). Так, доли ВЖК при использовании гексана и хлороформа относительно близки между собой, составляя, соответственно, 25,8 и 21,7\%, а при использовании этилацетата доля ВЖК гораздо больше $(39,6 \%)$. Доля траметеноловой кислоты приблизительно одинакова в гексановом $(2,6 \%)$ и этилацетатном $(2,2 \%)$ экстрактах и в обоих случаях меньше доли альдегида траметеноловой кислоты, а при использовании хлороформа она значительно выше $(11,5 \%)$ и преобладает над содержанием альдегида.

Среди тритерпеноидов преобладают производные ланостана: ланостерин, инотодиол (доминирующий компонент), траметеноловая кислота и ее альдегид, составляющие в сумме до 74\% (в хлороформном экстракте) от зарегистрированных в экстракте соединений. Инотодиол, траметеноловая кислота и ее альдегид являются специфическими компонентами березового гриба [11], составляют вместе около 50-60\% от суммы соединений экстракта.

Необходимо отметить, что условия и длительность экстракции органическим растворителем могут значительно влиять на количественный выход экстракта. Так, в нашей работе двухчасовое кипячение сырья в хлороформе при двадцатикратном объеме экстрагента над массой сырья привело к выходу 1,2 мг экстракта из 1 г сырья (табл. 2). В работе [12] авторами из 4 кг сырья чаги хлороформом (10 л) выделено 150 г экстракта в сухом остатке (37,5 мг экстракта из 1 г сырья) при 7-дневной экстракции при $50{ }^{\circ} \mathrm{C}$ в автоматическом перколяторе. Разделение компонентов авторы проводили препаративной колоночной хроматографией, они приводят результаты выхода ланостановых тритерпеноидов: ланостерин 2,2 г, инотодиол 25,2 г, траметеноловая кислота 11,8 г, альдегид траметеноловой кислоты 2,4 г. Как и в нашей работе, инотодиол доминирует среди производных ланостана, а содержание траметеноловой кислоты преобладает над содержанием альдегида траметеноловой кислоты (при использовании для экстракции хлороформа).

Инотодиол проявляет in vitro выраженную противоопухолевую активность [12-14]. Перспективны дальнейшие экспериментальные и клинические фармакологические исследования инотодиола, а также траметеноловой кислоты и ее альдегида, поэтому извлечение этих соединений из чаги с помощью органических растворителей актуально.

\section{Bblвodbl}

1. Методом ГХ-МС установлено, что соединения водно-парового дистиллята чаги более чем на $90 \%$ состоят из высших жирных кислот $\mathrm{C}_{16}-\mathrm{C}_{18}$.

2. Гексан, хлороформ и этилацетат экстрагируют из чаги ВЖК $\mathrm{C}_{16}$ и $\mathrm{C}_{18}$ и тетрациклические тритерпеноидные соединения. Количественный выход экстракта в расчете на массу сырья при одинаковых условиях и длительности экстракции обратно пропорционален полярности органического растворителя.

3. Среди тритерпеноидов доминируют специфические компоненты чаги - инотодиол (преобладающий и биологически активный компонент), траметеноловая кислота и ее альдегид, составляющие вместе 50-60\% компонентов экстрактов, полученных с применением гексана, хлороформа или этилацетата. Их извлечение из чаги с помощью органических экстрагентов актуально для продолжения экспериментальных и клинических фармакологических исследований.

\section{Список литературы}

1. Sen T., Samanta S.K. Medicinal plants, human health and biodiversity: a broad review // Advances in biochemical engineering/biotechnology. 2015. Vol. 147. Pp. 59-110.

2. Song F.Q., Liu Y., Kong X.S., Chang W., Song G. Progress on understanding the anticancer mechanisms of medicinal mushroom: Inonotus obliquus // Asian Pacific Journal of Cancer Prevention. 2013. Vol. 14. N3. Pp. 1571-1578.

3. Сысоева М.А., Юмаева Л.Р., Гамаюрова В.С., Зиятдинова Г.К., Будников Г.К., Халитов Ф.Г. Сравнительная характеристика антиоксидантной активности водных и спиртовых извлечений чаги // Химия растительного сырья. 2009. №2. С. 121-124.

4. Сысоева М.А., Хабибрахманова В.Р., Гамаюрова В.С. Исследование золя водных извлечений чаги. ХІІІ. Биологически активные вещества коллоидной системы, формируемой после удаления дисперсной фазы из водного извлечения чаги хлористоводородной кислотой // Химия растительного сырья. 2009. №3. С. 151-156.

5. Сысоева М.А., Хабибрахманова В.Р., Гамаюрова В.С., Кыямова Г.И. Разделение водных извлечений чаги с использованием этилацетата. IV. Состав веществ фенольной и терпеновой природы, отделяемых из водного извлечения чаги этилацетатом // Химия растительного сырья. 2009. №4. С. 117-122. 
6. Mazurkiewicz W. Analysis of aqueous extract of Inonotus obliquus // Acta Poloniae Pharmaceutica - Drug Research. 2006. Vol. 63. N6, Pp. 497-501.

7. Nakajima Y., Sato Y., Konishi T. Antioxidant small phenolic ingredients in Inonotus obliquus (persoon) Pilat (Chaga) // Chemical \& pharmaceutical bulletin (Tokyo). 2007. Vol. 55. N8. Pp. 1222-1226.

8. Zheng W.F., Liu T., Xiang X.Y., Gu Q. Sterol composition in field-grown and cultured mycelia of Inonotus obliquus // Acta pharmaceutica Sinica. 2007. Vol. 42. N7. Pp. 750-756.

9. Zheng W.F., Zhao Y.X., Zhang M.M., Yin Z.J., Chen C.F., Wei Z.W. Phenolic compounds from Inonotus obliquus and their immune-stimulating effects // Mycosystema. 2008. Vol. 27. N4. Pp. 574-581.

10. Liu C., Zhao C., Pan H.H., Kang J., Yu X.T., Wang H.Q., Li B.M., Xie Y.Z., Chen R.Y. Chemical constituents from Inonotus obliquus and their biological activities // Journal of natural products. 2014. Vol. 77. N1. Pp. 35-41.

11. Kahlos K., Hiltunen R., V. Schantz M. 33-Hydroxy-lanosta-8,24-dien-21-al, a new triterpene from Inontus obliquus // Planta medica. 1984. Vol. 50. N2. Pp. 197-198.

12. Nomura M., Takahashi T., Uesugi A., Tanaka R., Kobayashi S. Inotodiol, a lanostane triterpenoid, from Inonotus obliquus inhibits cell proliferation through caspase-3-dependent apoptosis // Anticancer research. 2008. Vol. 28. N5A. Pp. 2691-2696.

13. Zhong X.H., Wang L.B., Sun D.Z. Effects of inotodiol extracts from Inonotus obliquus on proliferation cycle and apoptotic gene of human lung adenocarcinoma cell line A549 // Chinese journal of integrative medicine, 2011. Vol. 17. N3. Pp. 218-223.

14. Zhao L.W., Zhong X.H., Yang S.Y., Zhang Y.Z., Yang N.J. Inotodiol inhibits proliferation and induces apoptosis through modulating expression of cyclinE, p27, bcl-2, and bax in human cervical cancer HeLa cells // Asian pacific journal of cancer prevention. 2014. Vol. 15. N7. Pp. 3195-3199.

Поступило в редакичю 27 марта 2015 г.

После переработки 6 апреля 2015 г. 
Slizhov Yu.G., Khasanov V.V., Chumakov A.A.* CHEMICAL COMPOSITION OF WATER-STEAM DISTILLATE AND ORGANIC EXTRACTS OF RAW MEDICINAL BIRCH FUNGUS CHAGA INONOTUS OBLIQUUS (PERS.) PILAT

National Research Tomsk State University, pr. Lenina, 36, Tomsk, 634050 (Russia),

e-mail: anton.doktor.tomsk@mail.ru

Components of water-steam distillate and organic extracts of raw natural medicinal birch mushroom Chaga, Inonotus obliquus (Pers.) Pilat, are studied. Higher fatty acids $\mathrm{C}_{16}-\mathrm{C}_{18}$ constitute more than $90 \%$ of compounds in water-steam distillate. Hexane, chloroform and ethyl acetate extract higher fatty acids $\mathrm{C}_{16}, \mathrm{C}_{18}$ and tetracyclic triterpenoids. The total quantitative content of compounds in the organic extracts is inversely proportional to the polarity of the solvent. Specific tetracyclic lanostane triterpenoids (inotodiol, trametenolic acid and 3ß-hydroxylanosta-8,24-dien-21-al) constitute 50-60\% of compounds in organic extracts. The inotodiol is prevailing component of organic extracts. It was reported to exhibit in vitro powerful antitumor activity. Further study of biological activity is needed. Therefore, the extraction of Chaga with organic solvent is useful for experimental and clinical pharmacological studies of specific tetracyclic lanostane triterpenoids (inotodiol, trametenolic acid and $3 \beta-$ hydroxylanosta-8,24-dien-21-al).

Keywords: birch fungus, Chaga, Inonotus obliquus (Pers.) Pilat, carboxylic acids, triterpenoids.

\section{References}

1. Sen T., Samanta S.K. Advances in biochemical engineering/biotechnology, 2015, vol. 147, pp. 59-110.

2. Song F.Q., Liu Y., Kong X.S., Chang W., Song G. Asian Pacific Journal of Cancer Prevention, 2013, vol. 14, no. 3, pp. 1571-1578.

3. Sysoeva M.A., Jumaeva L.R., Gamajurova V.S., Zijatdinova G.K., Budnikov G.K., Halitov F.G. Himija rastitel'nogo syr'ja, 2009, no. 2, pp. 121-124. (in Russ.).

4. Sysoeva M.A., Habibrahmanova V.R., Gamajurova V.S. Himija rastitel'nogo syr'ja, 2009, no. 3, pp. 151-156. (in Russ.).

5. Sysoeva M.A., Habibrahmanova V.R., Gamajurova V.S., Kyjamova G.I. Himija rastitel'nogo syr'ja, 2009, no. 4, pp. 117-122. (in Russ.).

6. Mazurkiewicz W. Acta Poloniae Pharmaceutica - Drug Research, 2006, vol. 63, no. 6, pp. 497-501.

7. Nakajima Y., Sato Y., Konishi T. Chemical \& pharmaceutical bulletin (Tokyo), 2007, vol. 55, no. 8, pp. 1222-1226.

8. Zheng W.F., Liu T., Xiang X.Y., Gu Q. Acta pharmaceutica Sinica, 2007, vol. 42, no. 7, pp. 750-756.

9. Zheng W.F., Zhao Y.X., Zhang M.M., Yin Z.J., Chen C.F., Wei Z.W. Mycosystema, 2008, vol. 27, no. 4, pp. 574581.

10. Liu C., Zhao C., Pan H.H., Kang J., Yu X.T., Wang H.Q., Li B.M., Xie Y.Z., Chen R.Y. Journal of natural products, 2014, vol. 77, no. 1, pp. 35-41.

11. Kahlos K., Hiltunen R., V. Schantz M. Planta medica, 1984, vol. 50, no. 2, pp. 197-198.

12. Nomura M., Takahashi T., Uesugi A., Tanaka R., Kobayashi S. Anticancer research, 2008, vol. 28, no. 5A, pp. 26912696.

13. Zhong X.H., Wang L.B., Sun D.Z. Chinese journal of integrative medicine, 2011, vol. 17, no. 3, pp. 218-223.

14. Zhao L.W., Zhong X.H., Yang S.Y., Zhang Y.Z., Yang N.J. Asian pacific journal of cancer prevention, 2014, vol. 15, no. 7, pp. 3195-3199.

Received March 27, 2015

Revised April 6, 2015

\footnotetext{
* Corresponding author.
} 
